\title{
Documentaries use for the design of learning activities
}

\author{
Mr. Abdallah hariri ${ }^{1}$, Pr. Hichame Fihri Fassi ${ }^{2}$ \\ ${ }^{\prime}$ (Faculté des sciences et techniques de Settat (FSTS), Km 3, Route de Casablanca, 26000, Settat) \\ ${ }_{2}^{2}$ (Faculté des sciences et techniques de Settat (FSTS), Km 3, Route de Casablanca, 26000, Settat)
}

\begin{abstract}
Documentaries used in the training field constitute the rich sources of information. They have the advantage to associate the elements of knowledge with events which request the episodic memory of the learner. Thus, these documentaries increase the probability of retention of knowledge they convey. However, the logical sequence of knowledge does not guarantee an efficient construction which can be mobilized in situations of action. In this paper, we seek how to benefit from the potential of these documentaries to promote the construction and mobilization of knowledge by the learner in an elearning platform. Particularly, we propose a method allowing segmenting the contents of a documentary to design learning activities. Based on a case study related to the field of mechatronics, we begin by segmenting the content of a documentary in terms of elements of knowledge (facts, concepts, procedures, and rules) then we connect with each of these problems they seek to find answers. We reorganize learning activities to promote the acquisition and mobilization of knowledge by the learner. We conclude by proposing a pedagogical scenario to implement these activities in elearning platform.
\end{abstract}

Keywords: LMS, IMS-LD, Documentary, Design, Elearning

\section{INTRODUCTION}

In the educational environment, the use of audiovisual dates back several years and it relies on several models ranging from simple teaching aids to the interactive learning environments. This use covers several fields, which physics (Constantinou and Papadouris, 2004), mathematics (Blisset and Atkins, 1993), sports (Guadagnoli, Holcomb and Davis, 2002; Horn, Williams and Scott, 2002), health care (Hill, Hooper and Wahl, 2000), and therapeutic counseling (Urdang, 1999).

Hereinafter, we consider a video documentary or one of these parts as a digital resource that we seek to exploit to design learning activities to be distributed either locally or via the web. We seek to operate more accurately the power of video documentaries to be exploited in face mode for designing learning activities.

\section{THE KNOWLEDGE CONVEYED BY A DOCUMENTARY}

In the most diverse training fields, documentaries are used to convey face mode that can be used for many purposes contents:

- help building a new knowledge

- help consolidating an acquired knowledge

- overcome the constraints related to the acquisition of a type of knowledge

- etc.

Generally, the conveyed content by such a support are implicit and they can not be used by the learner as such after having been explained. The explanation is the result of an operation of expert interpretation which depends heavily on the context in which it was held.

\section{EXTENDING THE CONTENT OF A DOCUMENT}

The explanation content we just mentioned is not sufficient to facilitate educational use, we must complete it by action annotation which enriches the different contents by the addition of supplementary information.

In this sense, an annotation is a generic term which includes both adding an unconstrained information that adding a well-trained information called metadata

Among the diversity of metadata standards that describe digital resources, there is the standard "Learning Object Metadata (LOM)", which is oriented towards the description of resources for educational purposes.

The conceptual model of the LOM metadata standard is divided into nine categories, each doing a clearly defined function (General, Lifecycle, Meta-metadata, Technical, Educational, Rights, Relation, Comment, and Classification). Each category contains a number of description elements.

In the study case we present below, we especially insist on the "proposed use" of the "teaching" element to facilitate the different fragments use of the instructional designer scenario 


\section{CASE STUDY: SEGMENTATION OF A DOCUMENTARY CONTENT}

In this case study, we focus on the fragmentation of a video documentary about a mecha-tronic taught as a subject at the cycle "Engineer". This is actually a free video broadcast on youtube and adopted by the department of mechanical FST Settat city to introduce the basic knowledge about mecha-tronics a group of 30 engineering students pursuing their education in the fourth grade "industrial engineering".

The $40 \mathrm{~min} 53 \mathrm{sec}$ video describes a traditional approach to achieve a quadrotor (a machine whose engine part consists of four rotating propellers connected to four rotors). In quadrirotor subject of the video, the narrator distinguishes the following four subsystems:

- Power

- Electronic hardware - The control part

- Mechanical hardware

- The software

Our segmentation method touches these four sub-systems and is based primarily on the isolation elements having a content items which presents a semantic consistency and whose intention of the narrator keeps stability.

We consider any sequence that conveys segment content with a coherent educational performance (relative to the curriculum in question) and that keeps steady pedagogical intention underlying the sequence. We then associate with each segment for it purports to convey and a proposal for an educational use.

We used the free software EKD which allows for treatments (including segmentation) post-production on a video and / or a sequence of its segments.

\begin{tabular}{|c|c|c|}
\hline Segment & What it purports to convey & Can be used for \\
\hline S1 & $\begin{array}{l}\text { Calculators and sensors presentation (accelerometer, } \\
\text { Gyrometers, GPS, Rangefinders, Barometric } \\
\text { Magnetometer) }\end{array}$ & $\begin{array}{l}\text { Introduce : } \\
-\quad \text { the sensor concept and its various types } \\
\text { - } \quad \text { the control concept in an automated system }\end{array}$ \\
\hline S2 & Quadrirotor behavior simulation with sensors & $\begin{array}{l}\text { Introduce : } \\
-\quad \text { system behavior simulation } \\
-\quad \text { correction }\end{array}$ \\
\hline S3 & The mechanical structure conception with AutoCad & $\begin{array}{l}\text { Introduce : } \\
\text { - } \quad \text { functional analysis } \\
\text { - Mechanical structure conception of an automated system }\end{array}$ \\
\hline S4 & Sizing uadrirotor & $\begin{array}{l}\text { Introduce : } \\
\text { - } \quad \text { System sizing } \\
\text { - } \quad \text { The use of knowledge bases for sizing a system. }\end{array}$ \\
\hline S5 & Components choice & $\begin{array}{l}\text { Introduce the concepts of: } \\
\text { - engine } \\
\text { - control }\end{array}$ \\
\hline S6 & Setting and testing & $\begin{array}{l}\text { Introduce the concepts of: } \\
\text { - } \quad \text { fixing } \\
\text { - } \quad \text { protection } \\
\text { - } \quad \text { test } \\
\end{array}$ \\
\hline
\end{tabular}

TAB 1 - Table summarizing the segmentation method on our study's document object

Analysis of the various elements associated with each of the mentioned segments allowed us to identify relevant knowledge that we have grouped by the type of D. Marril

\begin{tabular}{|l|c|c|c|c|}
\cline { 2 - 4 } \multicolumn{1}{c|}{} & Fait & Concept & Principe & Procédure \\
\hline Quadrirotor & $\checkmark$ & & & \\
\hline Quadrirotor modelling & & & $\checkmark$ & \\
\hline The automated system (SA) & & $\checkmark$ & & \\
\hline Control in SA & & $\checkmark$ & & \\
\hline Simulating the behavior of a SA & & $\checkmark$ & & $\checkmark$ \\
\hline The correction in SA & & $\checkmark$ & & $\checkmark$ \\
\hline The mechanical conception & & $\checkmark$ & & $\checkmark$ \\
\hline Sizing & & & & $\checkmark$ \\
\hline Engine & & $\checkmark$ & & $\checkmark$ \\
\hline Fixing & & $\checkmark$ & & $\checkmark$ \\
\hline Protection & & $\checkmark$ & & $\checkmark$ \\
\hline SA control & & $\checkmark$ & & \\
\hline Model test & & $\checkmark$ & & \\
\hline
\end{tabular}

TAB 2 - Grouped knowledge according to D. Merrill typology

In the following, we will refer to $\mathrm{TAB} 2$ and try to conceive a focus learning system on an approach by problems which allows us to develop among learners the knowledge herein. We particularly seek educational pretexts that allow us to deal with all relating issues:

- to the modeling of an automated system

- to the control in an automated system 
- to the simulate of an automated system behavior

- to the translation of the an automated functional structure system

- to the mechanical conception of an automated system

- to the manufacture of an automated mechanical system

- to the programmed control of an automated system

- to the model test of an automated system.

\begin{tabular}{|c|c|c|}
\hline Activities & Activity title & Problem(s) in which the activity responds \\
\hline A1 & Modeling of an automated system & $\begin{array}{l}\text { P1: How to develop models (schematic and formal) that } \\
\text { describe the behavior of an automated system. } \\
\text { P2: How to determine the main factors DEPOND the behavior } \\
\text { of an automated system. }\end{array}$ \\
\hline A2 & Control in an automated system & $\begin{array}{l}\text { P3: How to set up a system to control the behavior of an } \\
\text { automated system. }\end{array}$ \\
\hline $\mathbf{A 3}$ & Behavior simulating of an automated system & $\begin{array}{l}\text { P4: How to simulate the behavior of an automated system. } \\
\text { P5: How to set up a system of correction. }\end{array}$ \\
\hline A4 & $\begin{array}{l}\text { The functional structure definition of an automated } \\
\text { system }\end{array}$ & $\begin{array}{l}\text { P6: How to determine the overall structure of an automated } \\
\text { system. } \\
\text { P7: How to define the functional structure of an automated } \\
\text { system. }\end{array}$ \\
\hline A5 & The mechanical conception of an automated system & $\begin{array}{l}\text { P8: How to define the mechanical architecture of an automated } \\
\text { system. } \\
\text { P9: How to design the mechanical components of this } \\
\text { architecture: } \\
\text { - Engine } \\
\text { - Setting } \\
\text { - Transmission } \\
\text { Protection. }\end{array}$ \\
\hline A6 & The manufacture of an automated mechanical system & $\begin{array}{l}\text { P10: How choir materials } \\
\text { P11: How to choose the machine tools } \\
\text { P12: How to define the machining processes. }\end{array}$ \\
\hline A7 & The programmed control of an automated system & $\begin{array}{l}\text { P 13: How to program the control part of an automated system. } \\
\text { P14: Understanding the interactions between the sensors and } \\
\text { actuators of an automated system. }\end{array}$ \\
\hline A8 & Model test of an automated system & $\begin{array}{l}\text { P15: How to test the actual operation of an automated system. } \\
\text { P16: Check the assumptions on the behavior of an automated } \\
\text { system. }\end{array}$ \\
\hline
\end{tabular}

TAB 3 - Table showing the selected activities for our learning system.

\section{LEARNING ACTIVITIES SCRIPTING}

To describe the effective sequence of the various selected activities for our learning system, we use the educational modeling language initiated by Kopper and adopted by IMS as a specification called IMS LD (Instructional Management System Learning Design). Indeed, Koper (2001) proposes to describe the learning units using modeling languages teaching that define the relationships between:

- the knowledge or skills goals

- actors learning

- the activities carried out

- environment and necessary content to the establishment of the learning situation

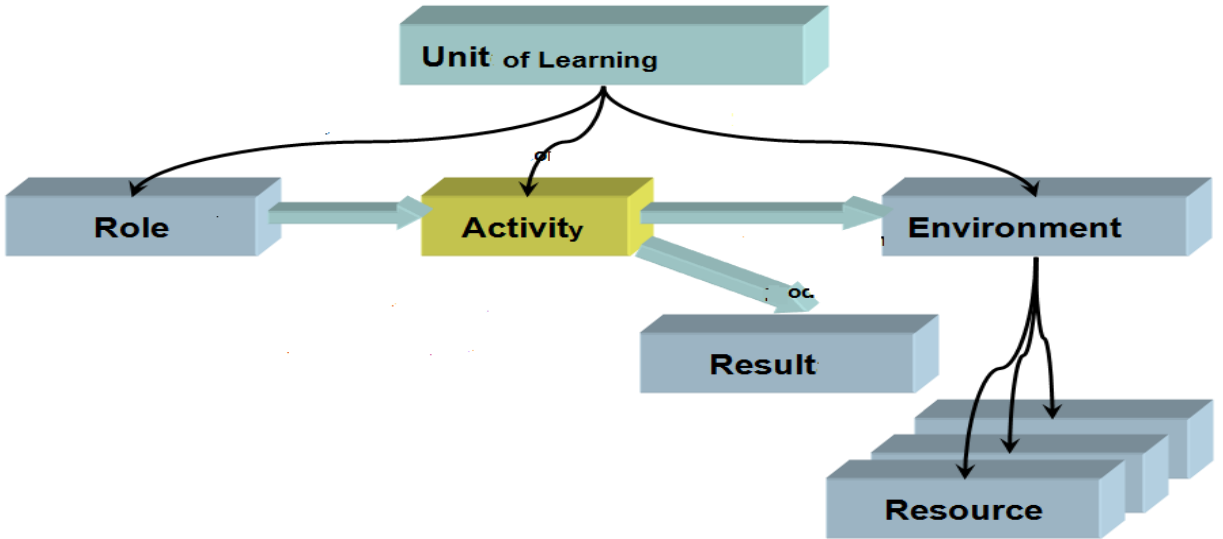

FIG. 1 - Architecture of a learning unit according to Rob Koper. 
Since then, several studies have succeeded and they all aim to make it easier for designers of learning systems while respecting the IMS LD specification.

We choose for this paper, the Pernin approach (2004) which aims to describe a learning unit for scenario which is nothing other than a description, made a priori the sequence of a learning unit aimed at the acquisition of a body of knowledge, specifying the roles, activities and resources for handling knowledge, tools, and necessary services for the implement activities.

To which we add an input by problems entry problems which the learning activities are trying to find response elements.

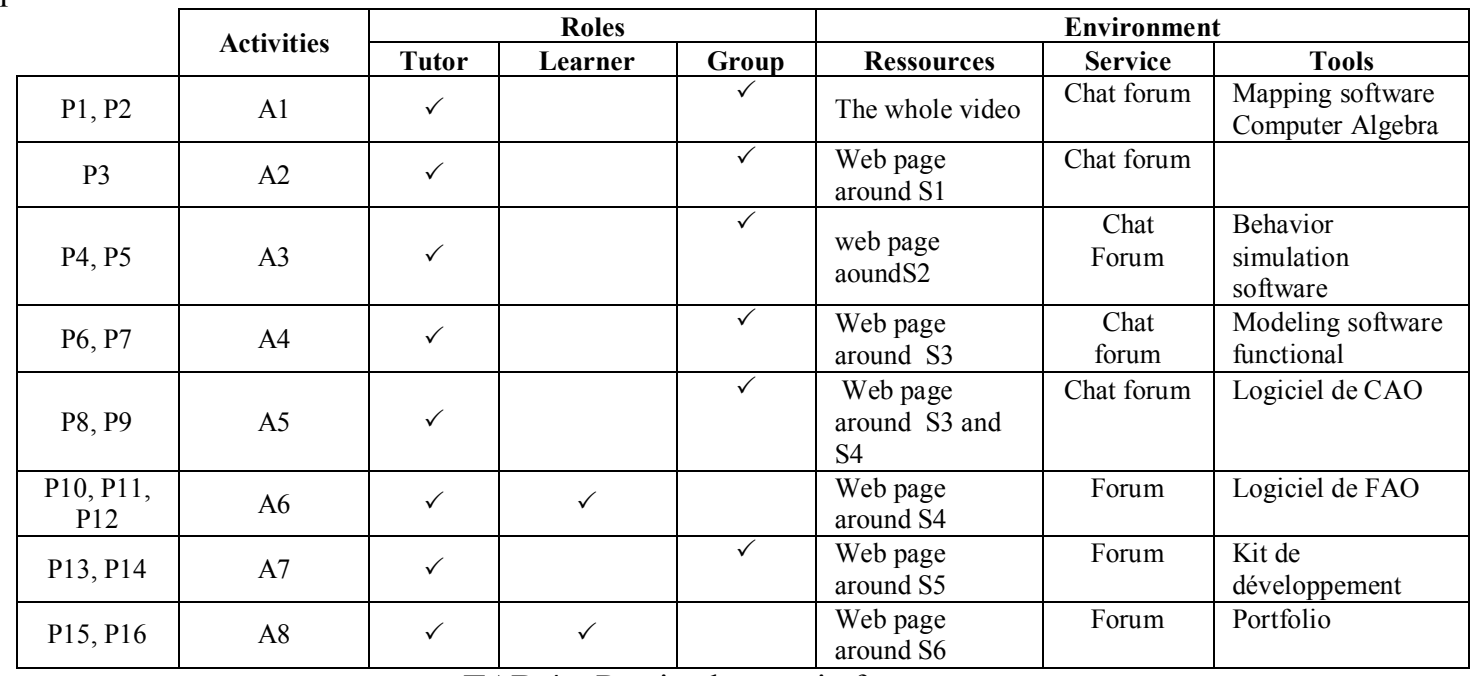

TAB 4 - Retained scenario for our case.

\section{CONCLUSION}

Although we applied this method in video documentaries for use in the field of training, it can be applied to other media resources (animation, sound files, images ...)

The transition of media resources use in face mode to a focus on distance learning use, requires a disciplined approach allowing help to the designer to:

- extract educational pretenses

- choose a pedagogical approach that determines the entries for educational pretenses

- script learning activities around the entrances and environments offered by distance learning platforms.

This work presents an attempt in this direction and we are experimentally validate to draw results will be other publications.

Books:

\section{REFERENCES}

[1] Lejeune (2004), IMS Learning Design, Étude d'un langage de modélisation pédagogique, article soumis à la revue DISTANCES et SAVOIR

\section{Chapters in Books:}

[2] P.O. Bishop, Neurophysiology of binocular vision, in J.Houseman (Ed.), Handbook of physiology, 4 (New York: Springer-Verlag, 1970) 342-366.

[3] W.J. Book, Modelling design and control of flexible manipulator arms: A tutorial review, Proc. 29th IEEE Conf. on Decision and Control, San Francisco, CA, 1990, 500-506.

[4] Koper, R,. (2003), Combining re-usable learning, resources and services to pedagogical purposeful units of learning. In A. Littlejohn (Ed.), Reusing Online Resources: A Sustainable Approach to eLearning (pp. 46-59). London: Kogan Page

[5] Koper, R. Olivier B., (2004), Representing the Learning Design of Units of Learning, Educational Technology \& Society, Vol. 7, n³, p. $97-111$

[6] Pernin, J.P., (2003) Objets pédagogiques : unités d'apprentissage, activités ou ressources ?, Revue "Sciences et Techniques Educatives", Hors série 2003 " Ressources numériques, XML et éducation", pp 179-210, avril 2003, éditions Hermès.

Web site:

[7] LOM (2002) LOM specification, Learning Object Metadata http://ltsc.ieee.org/wg12/, dernière consultation, Mars 2013. 